\title{
From Differentiation of the Expressive Effects to Conscious Use of Rhetorical Language
}

\author{
Yulan $\mathrm{Gu}$ \\ School of Foreign Languages, Sichuan University of Arts and Science, Dazhou, Sichuan, China
}

\begin{abstract}
The double predicate structures in English are examples of rhetorical use of language. The differentiation between the distinctive double predicate structure "verb + adjective" and the normal predicate structure "verb + adverb" and the subsequent choice in specific contexts is thus not only a matter of grammar rules on the surface, but, more substantively, a matter of conscious use of rhetorical language. The survey conducted among college English teachers in China into their differentiation between "verb + adjective" and "verb + adverb" showed that most respondents didn't distinguish very well the differing expressive effects caused by the choice of the adjectives or the adjectives' derivative adverbs in these two types of structures, and that the majority of the respondents had difficulty in making proper choices between them for specific contexts. Since the identification of a language structure is the prerequisite for its appropriate use, due attention in English teaching and learning should be paid to the delicate differences among similar language items and to their differing expressive effects to cultivate awareness and competence of conscious use of rhetorical language, enhancing overall language performance.
\end{abstract}

Index Terms - double predicate structures, expressive effects, conscious use of rhetorical language

\section{INTRODUCTION}

In English, a simple sentence usually expresses a state or an action, with the state indicated by the predicate structure of "linking verb + complement" and the action by that of "notional verb (+adverbial/object)". According to the conventional grammatical rules, the predicate structure indicating an action is not constructed by notional verbs in their active mood form followed only by adjectives or adjective phrases, with nothing else. The fact, however, is that in English there are sentences, like "The children sat stunned and silent", whose predicate structure is made up of the notional verb sat followed by an adjective phrase consisted of two adjectives stunned and silent, nothing else at all.

Such predicate structures obviously violate the accepted grammatical rule that the predicate structure is not formed by notional verbs followed by nothing but adjectives or adjective phrases, and thus have been attracting the attention of English grammarians. Henry Sweet (1891) thought the notional verbs in such structures are semi-linking verbs, and the adjectives part of the predicate structures as well as a modifier of the notional verbs (Ren Shaozeng, 1979, P. 2). In other words, the adjectives, along with the notional verbs preceding them, make the predicates of the sentences which they are in, and simultaneously, modify, like adverbials, the preceding verbs. Both George Curme (1953) and Otto Jespersen (1954) hesitated about the function of the adjectives in such structures, with Curme being not determined between the complement of the verbs and their appositive while Jespersen not so sure among complements, quasicomplements and adverbials (Ren Shaozeng, 1979, pp. 2-3). Geoffrey Leech and Jan Svartvik (1982), when discussing about the differences between adjectives and adverbs, didn't think the adjectives in such structures function as adverbials, but claimed that they are complements of subjects or objects. Randolph Quirk (1985, p. 1172) categorized such structures as verbless clauses, thinking of the adjectives in such structures as the complement and the verbs something like linking verbs with severe restrictions on the adjectives occurring in the complement. In China, many researchers also noticed and studied such structures. Ren Shaozeng (1978) initiated the study of such structures, borrowing Ganshina and Vasilevskaya's term "double predicate" (1964) to refer to them, and pursued comprehensive, intensive and systematic research about them in more than thirty years (Ren Shaozeng 1979; Ren Shaozeng 1988; Ren Shaozeng 2001; Ren Shaozeng 2010; Ren Shaozeng 2011). Lu Jinlin (1986) thought such structures are simply ambiguous and divergent grammatical phenomena, not necessary to be grammatically categorized. Ren Xiaojin (1986) argued that adjectives in such structures are more likely to be quasi-adverbials. According to the available documented literature, however, many other Chinese researchers (Xu Juntao 1995; Li Chongyue 2001; Hu Lanying, Du Xuemei, and Lv Shaoquan 2002; Tang Lu, Yu Jialou 2002; Zou Qiong 2005; Hu Yiqin 2007; Lin Lu, Han Bingbing 2015) agreed with Ren Shaozeng, accepted and adopted the borrowed term in their various studies of such structures. Whatever the English grammarians and most Chinese researchers thought of such structures, they simply studied such structures from the grammatical or the linguistic perspective, like the features, the discourse meaning, the cognitive mechanism of such structures or the functions of the adjectives in them, with the exception of Hu Lanying, Du Xuemei, and Lv Shaoquan (2002) and Zou Qiong (2005), who have slightly touched on their actual use. Such descriptive and explanatory studies are indeed helpful with English learners' understanding such structures grammatically and cognitively. They do not contribute a lot to English learners' appropriate use of such structures in production, which is in fact even more 
significant than theoretical understanding of their grammatical functions and cognitive mechanism. True understanding of their pragmatic issues and expressive effects of such structures determines whether or not language learners make appropriate, clever and rhetorical use of them in speaking and writing.

\section{The Rhetorical Nature of Double PredicAte Structures}

Adjectives are not grammatically allowed to follow notional verbs to make predicate structures, whereas (their derivative) adverbs often follow notional verbs functioning as the verbs' adverbials to make frequently-used predicate structures of "verb + adverb". So the double predicate structures are easily mistaken for the wrong forms of "verb + adverb" resulting from confusing the adjectives with their derivative adverbs. The actual existence of the double predicate structures of "verb +adjective" shows differentiating the double predicate structure "verb +adjective"1 from the structure "verb +adverb" and choosing them for specific contexts is more than a matter of grammar rules. Actually, the double predicate structure "verb +adjective" is a good example of rhetorical use of language. The double predicate structure's rhetorical nature can be well illustrated from four perspectives.

First of all, the rhetorical nature of the double predicate structures "verb + adjective" is determined by the communication nature of language itself. According to the western modern rhetoric, all communication activities are about rhetorical use of language. The double predicate structures are products of communication, either oral or written, where their users evaluate the need of specific contexts, differentiate the expressive effect of "verb +adjective" (like sat silent) and that of "verb +adverb" (like sat silently), and choose "verb +adjective" instead of "verb +adverb". In one word, choosing the double predicate structures is an episode of communication activities. The double predicate structures themselves are therefore examples of rhetorical use of language indicating the practice of an advanced language skill.

Secondly, their rhetorical nature is indicated by its creative violation of the grammatical rules through the cognitive means of metaphor and metonymy. Having explored the verbs which can be used in the double predicate structures from the perspective of the prototype theory and the conceptual metaphor, Ren Shaozeng (2010) concluded that such verbs transform their meanings through metaphor and metonymy, fall into the category of the linking verb be or become, and thus can be followed only by adjectives, functioning as predicates of the sentences where they are located. Even so, they differ from linking verbs in that they retain their conceptual meanings of notional verbs. In actual communication, however, their conceptual meanings are weakened, or exactly, not so important, since they are there as old information or one which can easily be inferred. That is, such verbs followed only by adjectives function as predicates, indicating both actions and the states, traits, or identities of those who carry out such actions, with the states, traits, or identities, not the actions, emphasized and focused on. By seeming to violate the grammar rules, the double predicate structures gains extra attention of their audience to outstand such states, traits, or identities as is conveyed by the adjectives, and present rhetorical effects by creatively stressing the chief expressing points.

Thirdly, their rhetorical nature lies in their conciseness and informativeness. According to Ren Shaozeng (1988), the double predicate structure is the linear presentation of the combination of one nominal predicate and one verbal predicate. In other words, a compound sentence, usually made up of one simple sentence with a verbal predicate and one with a nominal one, underlies a simple sentence with one double predicate. For example, the sentence The children sat stunned and silent is in fact the combined and condensed version of the sentences The children sat and The children were stunned and silent. These two sentences can have other combined and condensed versions (such as: The children sat and they were stunned and silent. / When the children sat, they were stunned and silent. / Sitting, the children were stunned and silent.). Similar to the simplified sentence with the double predicate structure sat stunned and silent, all these condensed versions follow the information processing rule that the new information precedes the old, and they seem to convey similar message. The truth, however, is that different sentence patterns transformed from the same underlying structure do not convey pragmatically identical meaning, and are usually appropriate for different specific situations (He Ziran 2011, p. 1). Consequently, differentiating among such confusing language forms and choosing one for a specific context is a matter of rhetorical use of language (Li Hong 2000, p. 32). What's more, compared with other combined and condensed versions, the double predicate structure is concise but informative, expressing much with as few words as possible. And that is the expected effects of using language rhetorically from time to time, going beyond literal use of language.

Last but probably most importantly, the double predicate structure is the written presentation of the foreground interest composition in photography, showing its users' intention of aesthetic and hierarchical presentation of the described. According to Qiu Wensheng (2015, p.123), the practice of using language rhetorically is a cognitive style of appreciating things and the cognitive subject's (e.g. the language user's in this context) aesthetic appeal and need in specific contexts. The double predicate structure is the written aesthetic presentation of things, a presenting practice illuminated from the foreground interest composition in photography. When photographing, people tend to place the focus in the foreground of the picture frame, which is called the foreground interest composition. Sometimes, however,

\footnotetext{
${ }^{1}$ Ren Shaozeng (1978) thought the verbs in the double predicate structures are mainly intransitive verbs (Transitive verbs, linking verbs, and even the double predicate structures themselves can be used too, though). In this paper, the verbs in the structure of "verb +adjective" specifically refer to intransitive verbs.
} 
the photographing focus is not positioned in the foreground, but is located far away in the background. Then the photographer will adjust the focus to the distant target by blurring the foreground, but not neglecting it all together, for the foreground is essential for the total effect of the picture - it functions for the viewers as a stepping stone into the focus and heightens the picture's sense of depth. Without the foreground, the focus may appear abrupt since the viewers would feel separated from the focus, and the picture would lose the sense of depth. The double predicate structure is the product of adopting such photographing technique in writing. The verbs in the double predicate structures, like the foreground in the photo, is not the intended message, but bridges the gap between the old information and the new or the intended information (conveyed by the adjectives), making the writing move on forward smoothly. In other words, the adjectives in the double predicate structures are what the structures are intended to emphasize, and the verbs are the essential transitions. Like what the foreground interest composition presents, the double predicate structure offers the context fluency and the audience the Déjà vu, expressing much more than the seemingly similar expression of "verb +adverb".

So, differentiating the two similar structures — "verb + adjective" and "verb + adverb" — and their expressive effects is more a practice of using language rhetorically. Whether English learners are able to make a proper choice for specific contexts between the two structures to some extent illustrates their awareness of using language rhetorically. This paper, therefore, is intended to conduct a survey about Chinese-context college English teachers ${ }^{2}$ identification and differentiation of the two structures, meaning to gain an insight into their awareness and competence of conscious use of rhetorical language.

\section{A Survey ABOut the DifFERENTIATING COMPETENCE OF EXPRESSIVE EFFECTS}

\section{A. The Design of the Survey}

As is mentioned above, this survey was conducted among college English teachers in China, intended to give some reference to the following two questions: (1) How do Chinese-context college English teachers perform when it comes to differentiating the expressive effects of the structures "verb + adjective" and "verb + adverb" and making choices between them for specific contexts? (2) Is there any correlation between the identification of "verb + adjective" and "verb + adverb"?

Writing is a good means to showcase learners' overall language competence and performance. But when specific structures are concerned, writing may not make the best policy. To use a language item, language learners, first of all, usually need to identify and truly understand it. If one cannot identify a language item, he or she is not likely to use it in their production. So, this paper is meant to investigate Chinese-context college English teachers' awareness and competence of rhetorical use of language by surveying their performance in identifying and differentiating the two similar structures and their expressive effects through a controllable exercise-gap-filling in a questionnaire.

The questionnaire was consisted of 24 gap-filling questions. Fifteen questions include double predicate structures "verb + adjective" and the other nine questions don't, which instead have the structure of "verb + adverb". The questions were created by replacing with blanks the adjectives or the adverbs in the original sentences which come from the Corpus of the Contemporary American English, which were for the respondents to fill out by choosing from the two offered alternatives or possibilities - A was the adjectives and B was their derivative adverbs. The verbs in the nine questions which don't have the "verb + adjective" structure were those appearing in the 15 questions. And the $25^{\text {th }}$ question was an open-ended one, inviting the respondents to write down their tips of answering questions. Each question was made up of several sentences, including one with the double predicate structure and its many adjacent sentences, offering respondents sufficient context to help them comprehend the intended information.

The respondents were asked to choose at least one answer for each question. The adjectives or adverbs in the original sentences were of course the expected right answers to these questions. But if the respondents chose both the adjectives and the adverbs for the 24 questions, they were thought to make correct choice, for if adverbs were put in the 15 blanks which were originally adjectives, they would be acceptable and make some sense. And it was the same case with the other nine blanks if adjectives were chosen.

The questionnaire was issued on the Chinese website, https://wjx.cn/, designed to conduct various surveys, reviews and voting. And the researcher posted the address in a QQ group of English teaching and research, initiated by Foreign Language Teaching and Research Press and mainly made up of college English teachers all over China, in the Wechat group of School of Foreign Languages where the researcher works, and in her Wechat moments, to invite college English teachers there to do the questionnaire.

\section{B. The Result and Analysis}

The survey lasted from July $23^{\text {rd }}, 2017$ to October $8^{\text {th }}$, and 62 questionnaires were valid. The 62 respondents (Chart 1$)$ came from 17 different provinces or places all over China, with two foreign IP addresses, which must be two Chinese teachers in the QQ group who happened to be on visit to universities abroad. And 23 respondents were shown to be

\footnotetext{
${ }^{2}$ As is discussed, the double predicate structures are examples of advanced language use, and Chinese college English teachers can be considered advanced English learners in China. The survey about their identification and differentiation of the double predicate structures can provide some insight into the awareness of using language rhetorically of common English learners in China.
} 
from Sichuan, with 8 from Dazhou, 12 from Chengdu, and 3 from other 3 different places). Given the fact that Sichuan is a big province with many universities and that the survey was carried out during the summer holiday when teachers may travel all over China on business, sightseeing, or visits back to their hometown, the respondents can be accepted as samples of Chinese-context college English teachers to certain extent, and the results of the questionnaires are not so likely to be homogenized so as to be able to shed some light on the Chinese-context college English teachers' awareness and competence of differentiating similar language items as well as that of using language rhetorically.

\begin{tabular}{|c|c|c|c|c|c|c|c|c|c|c|}
\hline \multicolumn{5}{|c|}{ 各省份咕写分布：查看地图分布情况 } & \multirow{2}{*}{\multicolumn{2}{|c|}{ 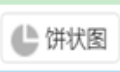 }} & \multirow{2}{*}{ () 圆环图 } & \multirow{2}{*}{ III柱状图 } & \multirow{2}{*}{\multicolumn{2}{|c|}{ 三条形图 }} \\
\hline 有份 & 数量 & 百分比 & 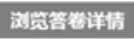 & 分类结计 & & & & & & \\
\hline 四川 & 23 & $37.10 \%$ & $\square$ & 때 & \multirow{17}{*}{ 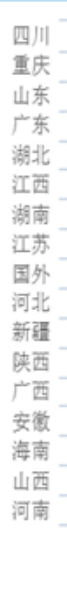 } & \\
\hline 需庆 & 7 & $11.29 \%$ & $\square$ & 岾 & & \multicolumn{5}{|c|}{$11.29 \%$} \\
\hline 山东 & 6 & $9.68 \%$ & $\square$ & uㅐ & & \multicolumn{5}{|c|}{ - } \\
\hline 广东 & 5 & $8.06 \%$ & $\square$ & 패 & & \multicolumn{5}{|c|}{$8.06 \%$} \\
\hline 湖北 & 4 & $6.45 \%$ & $\square$ & 패 & & \multicolumn{5}{|c|}{$223 \%$} \\
\hline 江西 & 2 & $3.23 \%$ & $\square$ & 밴 & & \multicolumn{5}{|c|}{$3.23 \%$} \\
\hline 湖南 & 2 & $3.23 \%$ & $\square$ & 때 & & \multicolumn{5}{|c|}{$3.23 \%$} \\
\hline 江苏 & 2 & $3.23 \%$ & $\square$ & ill & & \multicolumn{5}{|c|}{ a } \\
\hline 国外 & 2 & $3.23 \%$ & $\square$ & 形 & & \multicolumn{5}{|c|}{$3.23 \%$} \\
\hline 河北 & 2 & $3.23 \%$ & $\square$ & vill & & \multicolumn{5}{|c|}{$=$} \\
\hline 新䃌 & 1 & $1.61 \%$ & $\square$ & 때 & & \multicolumn{5}{|c|}{$=1.61 \%$} \\
\hline 陕西 & 1 & $1.61 \%$ & $\square$ & 酳 & & \multicolumn{5}{|c|}{$=1.61 \%$} \\
\hline 广西 & 1 & $1.61 \%$ & $\square$ & ill & & \multicolumn{5}{|c|}{$=$} \\
\hline 安徽 & 1 & $1.61 \%$ & $\square$ & 岾 & & \multicolumn{5}{|c|}{$=1.61 \%$} \\
\hline 海南 & 1 & $1.61 \%$ & $\square$ & iㅐ & & \multicolumn{5}{|c|}{$=$} \\
\hline 山西 & 1 & $1.61 \%$ & $\square$ & 岾 & & \multirow[t]{2}{*}{0} & \multirow[t]{2}{*}{10} & \multirow[t]{2}{*}{20} & \multirow[t]{2}{*}{30} & 40 \\
\hline 河南 & 1 & $1.61 \%$ & $\square$ & 때 & & & & & & \\
\hline
\end{tabular}

1. Identification and Differentiation of the Structures "verb + adjective" and "verb + adverb"

As is shown in Table 1, the respondents' average scoring rate of the 24 questions is $51.9 \%$, with $79.2 \%$ as the highest rate and $29.2 \%$ the lowest. Only 13 respondents score $60 \%$ or more, accounting for $20.1 \%$ of the total respondents, and none of them score $80 \%$ or more. When it comes to the 15 questions with the double predicate structure "verb + adjective", their average scoring rate is still lower, only $37.1 \%$, with $80 \%$ as the highest. And some respondents even didn't identify a single double predicate structure. There are 13 respondents scoring $60 \%$ or more, with two of them scoring $80 \%$. When the 9 questions with the structure "verb + adverb" are concerned, the average scoring rate is much better, reaching $76.5 \%$, with $100 \%$ as the highest and $11.1 \%$ the lowest. There are 53 respondents scoring $60 \%$ or more, with 14 of them scoring between $80 \%$ and $90 \%$ and 10 scoring $100 \%$.

\begin{tabular}{|c|c|c|c|}
\hline 3 & 24 questions & 15 questions with "verb + adjective" & 9 questions with "verb + adverb" \\
\hline average scoring rate & $51.88 \%$ & $37.10 \%$ & $76.52 \%$ \\
\hline the highest scoring rate & $79.17 \%$ & $80.00 \%$ & $100.00 \%$ \\
\hline the lowest scoring rate & $29.17 \%$ & 0 & $11.11 \%$ \\
\hline scoring rate $<60 \%$ & $79 \%$ & $79.03 \%$ & $14.52 \%$ \\
\hline $60 \% \leq$ scoring rate $<70 \%$ & $12.9 \%$ & $12.90 \%$ & $17.74 \%$ \\
\hline $70 \% \leq$ scoring rate $<80 \%$ & $8.1 \%$ & $4.84 \%$ & $29.03 \%$ \\
\hline $80 \% \leq$ scoring rate $<90 \%$ & 0 & $3.22 \%$ & $22.58 \%$ \\
\hline $90 \% \leq$ scoring rate $<100 \%$ & 0 & 0 & 0 \\
\hline scoring rate $=100 \%$ & 0 & 0 & $16.13 \%$ \\
\hline
\end{tabular}

These figures illustrate that most respondents (up to 85.5\%) performed well enough in identifying the structure "verb + adverb", with $38.7 \%$ of them doing it very well, and $16.1 \%$ of them excellently. Most respondents, however, did not perform well enough in differentiating the two confusing structures, with only $20.1 \%$ of them made $60 \%$ or more of the correct choices for specific contexts. It indicates that most of them can not differentiate the expressive effects of these two structures. And some respondents performed really bad in identifying the structure "verb + adjective", with only $20.9 \%$ of the total made $60 \%$ of the proper choices for specific contexts, but two of them did very well, identifying $80 \%$ of the 15 double predicate structures. It exemplifies that the difference in the expressive effects of the two similar structures has been noticed and that some English learners have the awareness of differentiating similar language items and their expressive effects. 
In one word, the survey seemed to imply that most Chinese-context college English teachers do not tend to do very well in differentiating the expressive effects of similar language structures, not showing strong enough awareness of such rhetorical use of language.

2. The Correlation between the Identification of "verb + adjective" and "verb + adverb"

Closely study individual performance of the respondents in the questionnaire discloses that those respondents who did well in the 15 questions with the double predicate structures didn't necessarily perform similarly well in the 9 questions without the double predicate structures, they were expected so, though. The underlying assumption is that those who identified the "verb + adjective" structures understand the true meaning of such structures and can distinguish them from the "verb + adverb" structure, while those who didn't identify the "verb + adverb" structures are not likely to identify the "verb + adjective" structures, for it's believed that it's hard for those who don't really understand the basics of language use to master something more advanced and complicated. But the survey shows that most of those who scored very high in the 15 questions turned out to score very low in the 9 questions.

For a better and a more precise insight into the respondents' performance, the researcher analyzed the correlation between the average scoring rate of the 15 questions with the structure "verb + adjective" and that of the 9 questions with the structure "verb + adverb". The Spearman correlation was as shown in Tab. 2. The figures show that there existed significantly negative correlation between them. That is, the better the respondents performed in the 15 questions, the worse they did in the 9 questions. To put it another way, if the respondents scored well in the 15 questions, they would usually score quite low in the 9 questions, or if they had very good scores in the 9 questions, they would usually score very bad in the 15 questions. The Spearman correlation analysis result is consistent with the then result of the questionnaire, but contrary to the assumption that advanced language skills are usually based on the basic ones, and that those who can properly use the advanced language skills can perform well in the less advanced ones.

The possible reason is likely to be that most respondents did not really have an insight into the delicate difference between the two structures and their expressive effects. They either chose adverbs for most or even all the questions by following the general grammar rules, or chose adjectives for most or even all questions because they had speculated the intention of the survey and answered the questions against the usual rules. This possibility may be verified and confirmed by the fact that no respondents offered their tips of answering the questionnaire, though not necessarily.

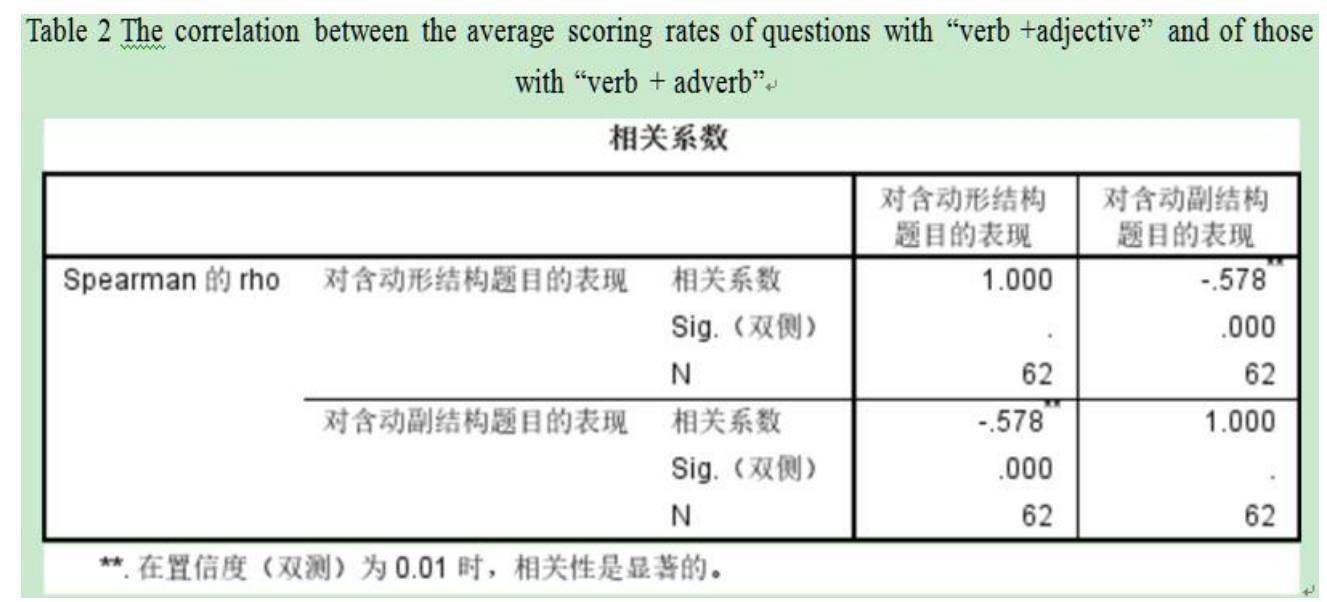

\section{CONCLUSION}

The double predicate structures present picturelike effects of the foreground interest composition in photography due to the smooth transition offered by the verbs in them, and the properly emphasized states, traits, or identities indicated by the adjectives. The use of the double predicate structures is not a simple activity of language use, but more an advanced practice of language use, e.g. rhetorical use of language. Use of such double predicate structures shows in some way Chinese-context college English teachers' awareness of rhetorical use of language. The survey seemed to indicate that most Chinese-context college English teachers have trouble in differentiating the expressive effects of the two similar structures — "verb + adjective" and "verb + adverb". Therefore, they are not likely to make fluent use of such structures in their production since understanding and identifying a language item is the prerequisite of its proper use.

Grammar rules contribute to the correctness of language use, but not the appropriateness, let alone a special expressive effect. The pragmatic and rhetorical knowledge of language and language use helps with what is more than correctness. On that account, in language learning and teaching, due attention should be paid to the delicate differences among similar words, structures and sentence patterns, and to their different expressive and aesthetic effects to cultivate awareness and competence of rhetorical use of language, enhancing the general language performance.

This paper is intended to explore Chinese-context college English teachers' awareness and competence of differentiating similar language items and using rhetorical language by surveying their identification and differentiation 
of the specific structures "verb + adjective" and "verb + adverb". There exists some imperfection about the questionnaire. First, there were only 62 valid questionnaires, and the samples were not large enough, which may not be various and comprehensive enough. Second, the number of questions with the structure "verb + adverb" was not the same as that of questions with the structure "verb + adjective". If the questions with the "verb + adverb" structure were as many as those with the other structure, the correlation between the average scoring rates of the two types of questions would be more explanatory and convincing. With all this imperfection, this study can serve as an initiating attempt for more valuable research about the actual use of the double predicate structures.

\section{ACKNOWLEDGMENTS}

This work was part of the research achievements of the Project "Corpus-driven Studies of the Cultivation of Rhetorical Language Competence in English Writing" (16SA0107), supported by Scientific Research Fund of SiChuan Provincial Education Department.

\section{REFERENCES}

[1] Curme, G. (1953). English Grammar. New York: Barnes \& Noble Inc.

[2] Ganshina, A. N. Vasilevskaya. (1964). English Grammar ( $9^{\text {th }}$ ed.). Moscow: Foreign Languages Publishing House.

[3] Geoffrey, L., Jan Svartvik. (1982). A Communicative Grammar of the English. London: Longman House.

[4] He Ziran. (2011). Some Thoughts on my Cognition of Pragmatics. Studies of the Modern Foreign Languages, 7, 1-4.

[5] Hu Lanying, Du Xuemei, Lv Shaoquan. (2002). On Simplification of English Language's Expression. Journal of Social Science of Jiamusi University 20. 3, 52-54.

[6] Hu Yiqin. (2007). The Cognitive Investigation of Double Predicate. Doctoral Dissertation. Nanjing: Nanjing Normal University.

[7] Jespersen, O. (1954). A Modern English Grammar on Historical Principles. London: Einar Munksgaard, GEORGE ALLEN \& UNWIN LTD.

[8] Li Chongyue. (2001). A Study of English Double Predicate and Its Relevant Characters. Jiangsu University of Science and Technology (Social Science) 1, 106-109.

[9] Li Hong. (2000). Grammar, Rhetoric and Grammatical Rhetoric. Shandong Foreign Language Teaching Journal, 4, $29-32$.

[10] Lin Lu, Han Bingbing. (2015). A Constructional Grammar Study of English Double Predicate Construction. Language Education 3. 2, 60-66.

[11] Lu Jinlin. (1986). A Second Study of the English Double Predicates. Foreign Language Research 3, 40-44.

[12] Qiu Wensheng. (2015). Cognitive Study of Rhetoric. Journal of Chongqing University of Technology (Social Science) 29. 12, 122-126.

[13] Quirk, R. (1985). A Comprehensive Grammar of the English Language. Sidney: Greenbaum.

[14] Ren Shaozeng. (1978). Verbs in the English Double Predicates. Journal of Foreign Languages 1, 11-18.

[15] Ren Shaozeng. (1979). The English Double Predicates. Studies of the Modern English 2, 11-19.

[16] Ren Shaozeng. (1988). A Third Study of the English Double Predicates. Journal of Foreign Languages 1, 21-27.

[17] Ren Shaozeng. (2001). A Discoursal Approach to Syntactic Structure. Journal of Foreign Languages 6, 1-12.

[18] Ren Shaozeng. (2010). Why is it Possible that a Material Process can also be a Relational Process? - A Study of the verbs in the double predicate clause from a cognitive-functional perspective. Journal of Foreign Languages 33. 2, 2-11.

[19] Ren Shaozeng. (2011). How do Notional Verbs Merge into the Relative Clause-A Study of the Double Predicate Clause from a Cognitive-Functional Perspective. Journal of Foreign Languages 34. 4, 21-31.

[20] Ren Xiaojin. (1986). Identification of the English Double Predicates. Foreign Language Research 2, 15-22、14.

[21] Sweet, H. (1891) A New English Grammar: logical and Historical. Oxford: Oxford University Press.

[22] Tang Lu, Yu Jialou. (2002). On the discourse meaning of dual predicate. Journal of Hefei University of Technology (Social Sciences) 16. 4, 122-124.

[23] Xu Juntao. (1995). Features of Verbs in the English Double Predicates. Journal of Fuzhou University (Social Science) 9. 4, 5759, 64.

[24] Zou Qiong. (2005). New Language Theories and Their Teaching Implications. Hunan Social Science, 11, 137-139.

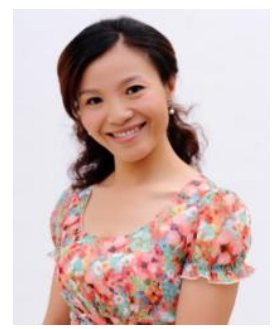

Yulan Gu was born in Guang'an, China, in 1976. She received her master's degree in English Language and Literature from Sichuan University, China, in 2007.

In the first three years of her teaching career, she taught primary students and middle school students English. Since 2002, she has been teaching English reading and writing at Sichuan University of Arts and Science. Now she is an associate professor there, mainly teaching English writing. She has published more than ten articles about English teaching, many of which are about the teaching of English reading and writing. Her writing course book, Basic English Writing: From Writing Purposes to Essays, was published by Southwestern University of Finance \& Economics Press last year. Now her research chiefly involves the teaching of English writing and that of writing-oriented reading.

Ms. Gu is a member of Sichuan Association for Applied Linguistics. She won third place in the teaching contest at Sichuan University of Arts and Science in 2003, and was awarded the title of Excellent Young Teacher by her university in 2012. In 2013, 2015, and 2016, she was the winner of the Second, the Third, and the First Coach Award in the Sichuan Provincial Final of 2013, 2015, and 2016 "FLTRP Cup" English Writing Contest. 